\title{
Karyomorphological study of Enhydra fluctuans Lour. (Asteraceae)
}

\begin{abstract}
M. S. Rahman*
Open School, Bangladesh Open University, Gazipur-1705

\author{
Revised: 11 March 2019 \\ Accepted: 06 May 2019
}

Received: 23 September 2018

Abstract

In the present study, karyomorphological features of Enhydra fluctuans Lour. were investigated. Orcein-staining was used for the authentic chromosomal characterization and identification. In $E$. fluctuans 'Simple Chromocenter Type' of interphase nuclei was observed with many small heterochromatin blocks after orcein staining. Prophase chromosomes showed 'Gradient Type' with orcein staining. This species was found to possess $2 n=10 x=110$ with basic chromosome number $x=11$ and this is probably the first report for this species. The centromeric formula of this species was ' $38 \mathrm{~m}+70 \mathrm{sm}+2 \mathrm{ac}$ '. The above features indicated that E. fluctuans is an advance polyploid with asymmetric karyotype. The total chromatin length (2n) was $295.92 \mu \mathrm{m}$. Individual chromosome length ranged from 1.84-4.26 $\mu \mathrm{m}$. The relative length of each chromosome ranged from 0.006-0.014. The above mentioned data will be useful for karyomorphological characterization of E. fluctuans from Bangladesh.
\end{abstract}

DOI: https://doi.org/10.3329/bjsir.v54i4.44562
Keywords: Cytogenetics; Karyomorphology; Orcein; Polyploidy; Enhydra fluctuans

\section{Introduction}

Enhydra fluctuans Lour., (Fam.: Asteraceae) a tropical herb, commonly known as Helencha or Harkuch is gaining lot of importance for its therapeutic potentials (Ali et al., 2013). The plant is herbaceous and aquatic; usually grow on the margins of ponds and ditches (Ahmed et al., 2008; Sharma et al., 2014). The species may grow up to a sea-level 1,800 m. It is able to reproduce by fragmentation and may be so abundant that it clogs water courses. This species is an old-world species, possibly of Indochinese origin, which occurs in tropical Asia and Africa. It is common to all countries of Southeast Asia (Ali et al., 2013). In Bangladesh, E. fluctuans grows in almost all districts. Besides using the young shoots of the plant as pot vegetable, its medicinal uses have also been highlighted (Ahmed et al., 2008). Apart from Bangladesh, in the North-Eastern states of India E. fluctuans has been considered as one of the important species of medicinal plants having wide range of therapeutic applications and has been used for years as traditional medicine in remote areas of this region (Sharma et al., 2014). Different extracts of Enhydra fluctuans have been tested for the presence or absence of primary and secondary bioactive compounds like carbohydrates, proteins, oils, alkaloids, and flavonoids. E. fluctuans has been found to be a rich source of flavonoids and moderate presence of alkaloids, tannins, phenolics and carbohydrates have been reported. The plant is also a rich source of $\beta$-carotene (Dewanji et al., 1993; Ghani, 2003; Satyajit, 2012) and was also found to be high on protein content. Presence of saponin too has been stated (Ghani, 2003; Hazra, 2012; Dutta, 2013). A novel bioactive isoflavone glycoside 4', 5, 6, 7-tetrahydroxy-8methoxyisoflavone-7-O- $\beta$-D galactopyranosyl- $(1 \rightarrow$ $3)-O-\beta$-D xylopyranosyl $(1 \rightarrow 4)-O$ - $\alpha$-1-rhamnopyranoside has been reported from the methanolic extract of the leaves of E. fluctuans (Sannigrahi et al., 2010). The plant also contains myricyl alcohol, kaurol, cholesterol, sitosterol, glucoside, sesquiterpene lactones including germacranolide, enhydrin, fluctuanin and fluctuandin, a number of diterpenoid acids and their isovalerate and angelate derivatives, stigmasterol, cholesterol, sitosterol, other steroids and gibberellins A9 and A13 have been isolated from this plant (Ghani, 2003).

Although E. fluctuans has considerable medicinal values, no report about the genetic information is available in Bangladesh (Ahmed et al., 2008). A few studies from different parts of the world tried to count the $2 \mathrm{n}$ chromosome numbers of this species (Fedorov, 1969; Ray, 1957; Baquar

*Corresponding author e-mail: shahidurbou@gmail.com 
and Askari, 1970a, b; Bhattacharyya and Sharma, 1970). Even there is no detail report about the mitotic cell division of this species. Except $2 n$ chromosome number limited cytogenetical information is available for this species. On the other hand, there was no available report on detail karyotype studies of this species. For this cytogenetically analysis is needed for authentic identification and characterization. For identification and characterization of a specimen, genomic information is essential. Karyotype analysis is one of the conventional methods that give a preliminary idea about the genome of a specimen. Study of staining properties of interphase nuclei and prophase chromosomes are other karyomorphological parameters. Tanaka (1971) classified the different types of interphase nuclei and prophase chromosomes on the basis of orcein staining property. Therefore, in the present study, conventional cytogenetical analysis has been carried out for authentic identification and characterization of Enhydra fluctuans found in Bangladesh.

\section{Materials and methods}

Live specimen of E. fluctuans was collected from the Botanical Garden, Department of Botany, University of Dhaka. Flower, fruits, stems, branches and leaves of the specimen was studied in Cytogenetics Laboratory for identifying the plant by consulting literatures (Ahmed et al., 2008). After confirming identification, healthy roots from $E$. fluctuans were collected and pre-treated with 8 -hydroxyquinoline $(0.002 \%)$ for 1 hour at room temperature followed by 15 minutes fixation in $45 \%$ acetic acid at $4{ }^{\circ} \mathrm{C}$ and preserved in $70 \%$ alcohol at $4^{\circ} \mathrm{C}$ for future use. It was then hydrolyzed in a mixture of $1 \mathrm{~N} \mathrm{HCl}$ and $45 \%$ acetic acid (2:1) at $65^{\circ} \mathrm{C}$ for 2.30 minutes. The root tips were stained and squashed in 1\% aceto-orcein for 3 hours (Sultana et al., 2011). Afterwards, this slide was observed under a compound microscope (Nikon Eclipse 100). The well spread and clear mitotic metaphase chromosomes were taken to analyze different karyotypic parameters. Centromeric formula was determined based on the position of centromere and the number of chromosomes (Levan et al., 1964). Different karyomorphological parameters, asymmetry and symmetry indices and different other parameters were calculated (Huziwara, 1962; Peruzzi and Eroĝlu, 2013; Greilhuber and Speta, 1976; Arno, 1963; Stebbins, 1971).

\section{Results and discussion}

Several small heterochromatic blocks scattered in the interphase nuclei and a big prominent conspicuous nucleolus of this species were observed after staining with orcein (Fig. 2A). Prophase chromosomes of E. fluctuans were stained darkly at one end and gradually faint to another end of chromosome with orcein (Fig. 2B). E. fluctuans was found to possess somatic chromosome number $2 n=110$ (Fig. 2C). Satellite or satellite bearing chromosomes was not found in this plant. Centromeric Formula, Mean Centromeric Asymmetry, Range of Chromosomal Length $(\mu \mathrm{m})$, Total Chromosome Length $(\mu \mathrm{m})$, Average Chromosome Length $(\mu \mathrm{m})$, Total Form (TF) Value (\%), Karyotype Asymmetry Index (\%), The Index of Karyotype Symmetry (Syi)\%, The Karyotype Asymmetry Degree according to Stebbins (1971) were calculated and these were $38 \mathrm{~m}+70 \mathrm{sm}+2 \mathrm{ac}, 24.80$, $1.84-4.26,295.92,2.69,37.22 \%, 62.78 \%, 59.28 \%, 2 \mathrm{~B}$, respectively (Table I).

Table I. Cytogenetical features of Enhydra fluctuans Lour.

\begin{tabular}{ll}
\hline Cytogenetical features & $: 110$ \\
\hline 2n Chromosome Complement & $: 0.006-0.014$ \\
Range of Individual Chromosome Length $(\mu \mathrm{m}): 1.84-4.26$ \\
Range of Relative Length (RL) & $: 23.08-45.83$ \\
Range of Centromeric Index (CI) & $: 38 \mathrm{~m}+70 \mathrm{sm}+2 \mathrm{ac}$ \\
Centromeric Formula & $: 24.8$ \\
Mean Centromeric Asymmetry & $: 1.84-4.26$ \\
Range of Chromosomal Length $(\mu \mathrm{m})$ & $: 295.92$ \\
Total Chromosome Length $(\mu \mathrm{m})$ & $: 2.69$ \\
Average Chromosome Length $(\mu \mathrm{m})$ & $: 37.22 \%$ \\
Total Form (TF) Value $(\%)$, & $: 62.78 \%$ \\
The Karyotype Asymmetry Index, ASK $\%$ & $: 59.28 \%$ \\
The Index of Karyotype Symmetry (Syi) $\%$, & $: 2 \mathrm{~B}$ \\
Karyotype Asymmetry Degree &
\end{tabular}

\section{Nature of heterochromatins}

The staining properties of interphase nuclei and prophase chromosomes sometimes provide additional karyomorphological features that help to characterize different specimens (Tanaka, 1971). The present study revealed the presence of thirty to forty prominent darkly stained heterochromatic blocks in the interphase nuclei of $E$. fluctuans (Fig. 2A). This type of staining of interphase nuclei could be regarded as 'Simple Chromocenter Type' (Tanaka, 1971). The prophase chromosomes of this species were stained darkly at one end and gradually faint to another end of chromosomes (Fig. 2B). So, this type of prophase chromosomes could be regarded as 'Gradient Type' (Tanaka, 1971). The above findings indicated the presence of 


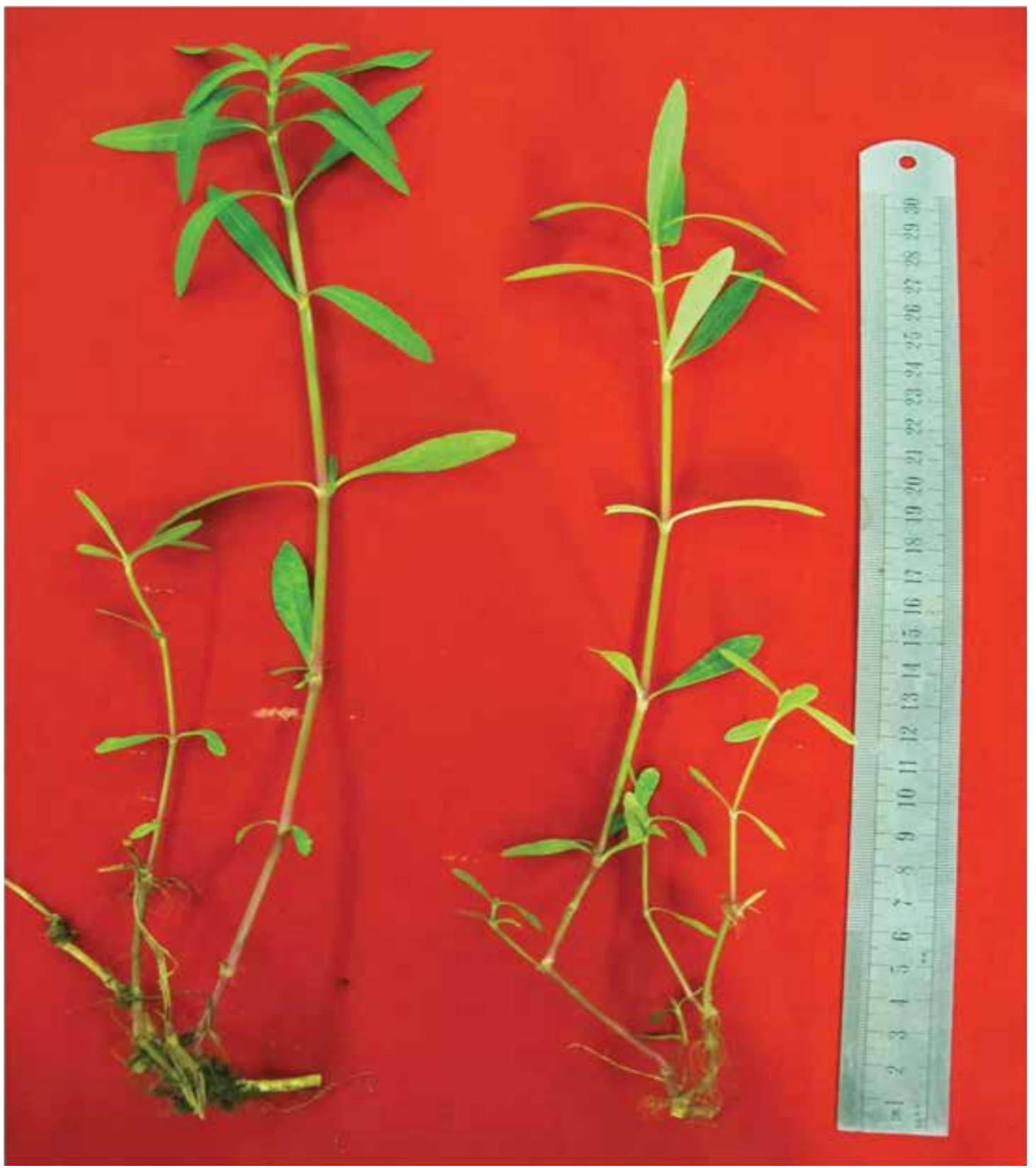

Fig. 1. Habit of Enhydra fluctuans Lour.

facultative heterochromatin which were aggregated in the interphase nuclei and then somehow had been gradually distributed in the prophase chromosomes. Generally, the localized heterochromatins, as observed in the interphase nuclei are not homogeneously distributed in the prophase chromosomes rather occupy different locations of prophase chromosomes. The present findings did not support the usual regulation regarding distribution of heterochromatin in prophase chromosomes. Presence of facultative heterochromatin might be one of the reasons for this disagreement. Therefore, this is the pioneer approaches by which this species could be characterized.

\section{Polyploidy}

In the present investigation E. fluctuans was found to possess $2 \mathrm{n}=110$ chromosomes with basic chromosome number $\mathrm{x}=11$ (Figs. 2C, 3). In this species, besides $2 \mathrm{n}=110$ chromosomes different chromosome numbers were reported earlier by different scientist viz. 2n=22 (Fedorov, 1969; Ray, 1957; 


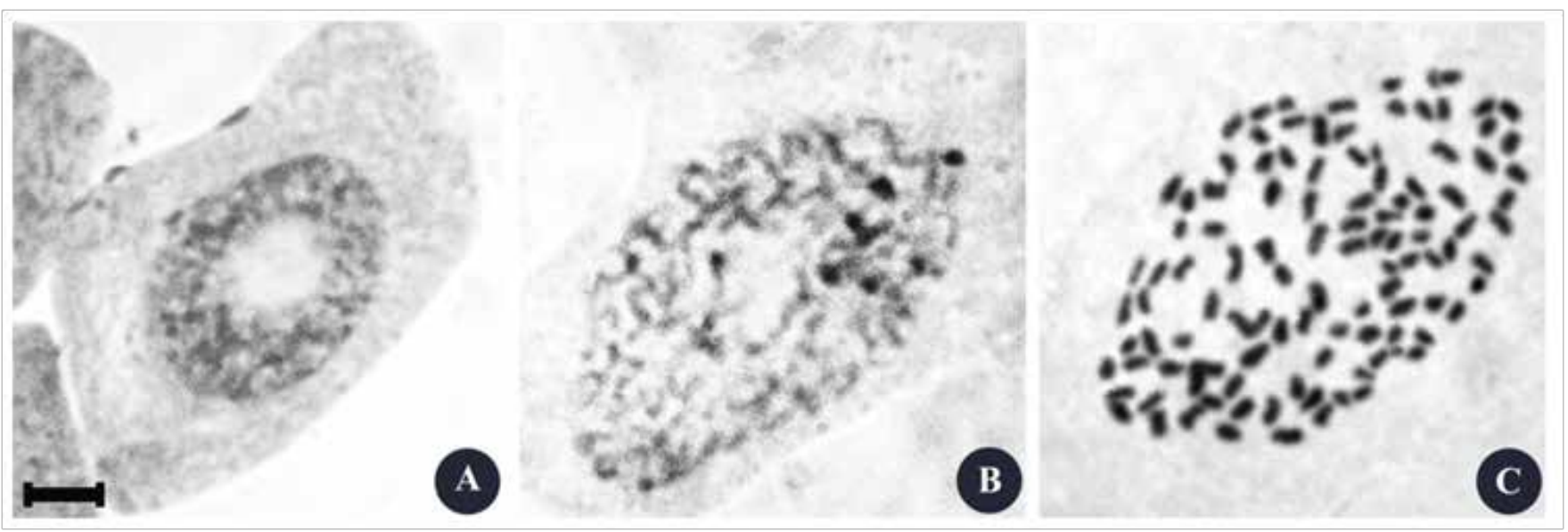

Fig. 2. Orcein stained mitotic cell division of Enhydra fluctuans A. Interphase nuclei, B. Prophase chromosomes and C. Metaphase chromosomes. Bar $=10 \mu \mathrm{m}$.

Baquar and Askari, 1970a, b) chromosomes with the basic chromosome number $\mathrm{x}=11,2 \mathrm{n}=30$ (Bhattacharyya and Sharma, 1970) chromosomes with the basic chromosome number $\mathrm{x}=15$ such basic chromosome number $(\mathrm{x}=4-19)$ was reported by Darlington and Wylie in 1950. In the present investigation, the basic chromosome numbers of E. fluctuans was $x=11$ which supports the findings of Ray (1957) and Baquar and Askari (1970a, b), but did not support the report of Bhattacharyya and Sharma (1970) and Darlington and Wylie (1950). If the basic chromosome number of this species is considered as $\mathrm{x}=11$, then specimen with $2 n=10 x=110$ observed in this study could be regarded as decaploid. This is the first report of somatic chromosome numbers on E. fluctuans from Bangladesh. $\mu \mathrm{m}$. Individual chromosome length ranged from 1.84-4.26 $\mu$ $\mathrm{m}$ (Table I). The relative length of each chromosome ranged from 0.006-0.014 (Table I). In this species, the range of chromosomal length was almost significant i.e. difference between the smallest and largest chromosome was about 2.42 $\mu \mathrm{m}$. As a result, gradual decrease of chromosomal length was observed in its karyotype (Table I). These features indicated that E. fluctuans has a strict asymmetric karyotype. Stebbins (1971) mentioned that the asymmetric karyotypes indicate advanced character and from that point of view E. fluctuans is a plant of advanced nature and could be considered as advanced species.

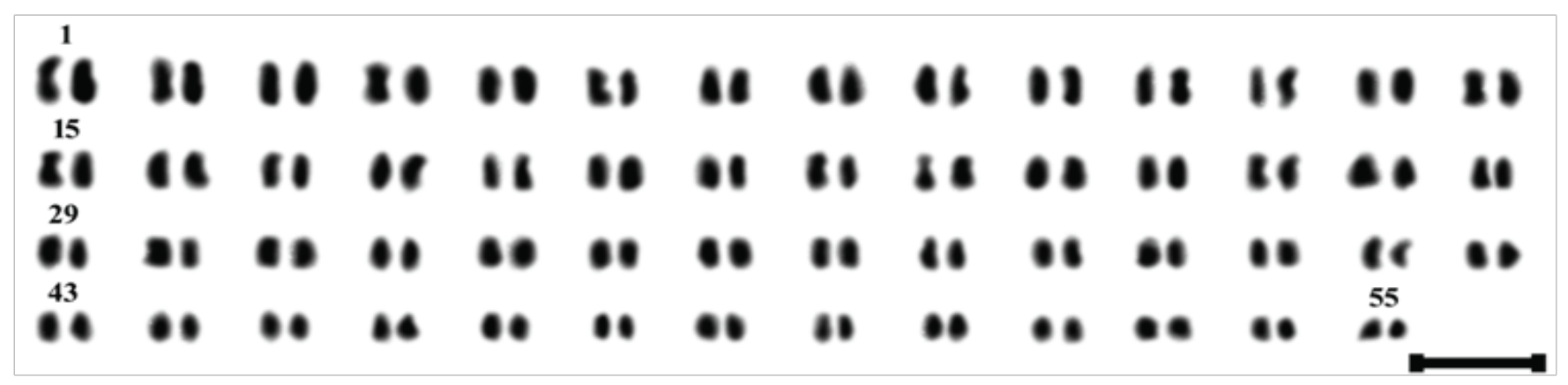

Fig. 3. Karyotype prepared from orcein stained mitotic metaphase chromosomes of Enhydra fluctuans. Bar $=10 \mu \mathrm{m}$.

\section{Karyotype analysis}

E. fluctuans was found to possess 38 metacentric, 70 submetacentric and 2 acrocentric chromosomes with a centromeric formula of ' $38 \mathrm{~m}+70 \mathrm{sm}+2 \mathrm{ac}$ ' (Fig. 3, Table I). The total length of $2 \mathrm{n}$ chromosome complement was 295.92
Probable reasons for the origin of submetacentric and acrocentric chromosomes

In this study, E. fluctuans was found to possess some submetacentric and few acrocentric chromosomes $(70 \mathrm{sm}+02 \mathrm{ac})$ with metacentric chromosomes (Fig. 3, Table 
I). The submetacentric and acrocentric chromosomes might be originated from metacentric chromosomes by some chromosomal aberration viz. terminal deletion, pericentric inversion, non-reciprocal or unequal translocation.

\section{Conclusion}

This study showed the nature of karyomorphological information of Enhydra fluctuans Lour. New chromosome number was probably the first report for this species and it might be helped to enhance the chromosomal database with detailed karyomorphological information of this species in Bangladesh.

\section{Acknowledgement}

The author is grateful to Cytogenetics Laboratory, Department of Botany, University of Dhaka, Bangladesh for providing all research facilities.

\section{References}

Ahmed ZU, Hassan MA, Begum ZNT, Khondker M, Kabir SMH, Ahmad M, Ahmed ATA, Rahman AKA and Haque EU (2008), Encyclopedia of Flora and Fauna of Bangladesh. Angiosperms: Dicotyledons (Balsaminaceae-Euphorbiaceae), 7 Vol., Asiatic Society of Bangladesh, Dhaka, pp 376-379.

Ali MR, Billah MM, Hassan MM, Dewan SMR and Emran MA (2013), Enhydra fluctuans Lour.: A review, Res J Pharm Tech. 6: 927-929.

Arno H (1963), Cytological studies in subfamily Carduoideae (Compositae) of Japan. IX. The karyotype analysis and phylogenetic considerations on Pertya and Ainsliaea, Bot Mag. 76: 32-39.

Baquar SR and Askari SHA (1970a), Chromosome numbers in some flowering plants of West Pakistan, Génet Ibér. 22: 1-11. DOI: $10.2307 / 2399924$

Baquar SR and Askari SHA (1970b), Chromosome studies in some flowering plants of West Pakistan, Génet. Ibér. 22: 41-51.

Bhattacharyya GN and Sharma AK (1970), Cytological study of some members of Compositae, Bull Bot Soc Ben. 24: 31-36. DOI: $10.2307 / 2656618$

Darlington CD and Wylie AP (1950), Chromosome atlas of flowering plants, George Allen and Unwin Ltd, Ruskin House Museum Street, London, U.K, pp 245-271.
Dewanji A, Matai S, Barik S and Nag A (1993), Chemical compositions of two semi-aquatic plants for food use, Pl Foods Hum Nutr 44: 11-16.

Dutta J (2013), Phytochemicals analysis and TLC fingerprinting of methanolic extracts of three medicinal plants, Int Res J Pharm. 4:123-126.

Fedorov ANA (1969), Chromosome numbers of flowering plants, Academy of Puschkinia (Liliaceae), Plant systematics and sciences of the USSR, V. L. Komarov Botanical Institute, Russia, pp 99.

Ghani A (2003), Medicinal plant of Bangladesh, Asiatic Society of Bangladesh, Dhaka, pp 3-17, 215, 323.

Greilhuber J and Speta F (1976), C-banded karyotypes in the Scilla hohenackeri group, S. persica, and Puschkinia (Liliaceae), Pl Syst Evo. 126: 149-188.

Huziwara Y (1962), Karyotype analysis in some genera of Compositae VIII. Further studies on the chromosome of Aster, American J Bot. 49: 116-119. DOI: 10.1002/j.1537-2197.1962.tb14916.x

Hazra H, Alfasane MA and Khondker M (2012), Biochemical composition of some selected aquatic macrophytes, Bangladesh, Lambert Academic Publishing.

Levan A, Fredga K and Sandberg AA (1964), Nomenclature for centromeric position on chromosomes, Hereditas 52: 201-220.

Peruzzi L and Eroĝlu HE (2013), Karyotype asymmetry: again, how to measure and what to measure? Comparative Cytogenetics 7: 1-9. DOI: 10.3897/CompCytogen.v7i1.4431

Ray M (1957), Cytology of Enhydra fluctuans Lour.., Bull Bot Soc Ben. 11: 54-55.

Sharma U, Borah VV, Saika KKR and Hazarika NK (2014), Enhydra fluctuans: A review on its pharmacological importance as a medicinal plant and prevalence and use in North-East India, Int $J$ Pharm Pharmac Sci. 6: 48-50.

Satyajit PD (2012), Natural flavonoids isolated from the leaves of Enhydra fluctuans inhibits cyclooxygenase-2 and 5-lipooxygenase inflammation in various models, Int $J$ Res Pharm Pharmacother. 1: 2278-2648. 
Stebbins GL (1971), Chromosomal evolution in higher plants, Addison-Wesley publishing company, California, USA, pp. 208.

Sannigrahi S, Mazumdar UK, Pal DK, Parida S and Jain S (2010), Antioxidants potential of crude extract and different fractions of Enhydra fluctuans Lour., Iranian J Pharm Res. 9: 75-82.
Sultana SS, Ara H and Alam SS (2011), Karyotype analysis with orcein and CMA in two species of Alocasia (Schott) G. Don, Bangladesh J Bot. 40: 53-56. DOI: 10.3329/bjb.v40i1.7998

Tanaka R (1971), Type of resting nuclei in Orchidaceae, The Bot Mag. 84: 118-122. DOI: org/10.15281/ jplantres1887.84.118 